\title{
MASTIGAÇÃO BOA RELACIONADA A MANUTENÇূ̃O DO PESO EM NONAGENÁrIOS E CENTENÁRIOS DURANTE A PANDEMIA: COVID-19
}

Camila Dalbosco Gadenz;; Escola de Medicina da PUCRS, Porto Alegre, Brasil; camiladgadenz@gmail.com Josemara de Paula Rocha*; Escola de Medicina da PUCRS, Porto Alegre, Brasil; josemara.rocha@hotmail.com

Álvaro Luiz Fortes*; Escola de Medicina da PUCRS, Porto Alegre, Brasil; alvarolforte@gmail.com Renata Breda Martins*; Escola de Medicina da PUCRS, Porto Alegre, Brasil; nutrirenatamartins@gmail.com Marlon Cássio Pereira Grigol*; Escola de Medicina da PUCRS, Porto Alegre, Brasil; marlonfisio@gmail.com Ângelo José Gonçalves Bós*; Escola de Medicina da PUCRS, Porto Alegre, Brasil; angelo.bos@pucrs.br

*Projeto de extensão Atenção Multiprofissional ao Longevo (AMPAL) do Instituto de Geriatria e Gerontologia da PUCRS, Porto Alegre, Brasil

\section{RESUMO}

Introdução: A imobilidade pode levar à perda ponderal em nonagenários e centenários, por aumentar o nível de sarcopenia nos mesmos. A qualidade da mastigação pode ser um fator protetor da perda ponderal em momentos de maior imobilidade, como durante a pandemia da COVID-19. Objetivos: Observar fatores relacionados à boa mastigação em nonagenários e centenários durante a pandemia da COVID-19. Métodos: Estudo transversal e observacional envolvendo nonagenários e centenários participantes do Projeto Atenção Multiprofissional ao Longevo, avaliados por smartphone entre abril e agosto/2020. A variável dependente foi boa autopercepção da mastigação e as variáveis independentes foram sexo, faixa etária (90-94, 95-99 e 100 anos ou mais), estado conjugal, autopercepção de saúde e perda subjetiva de peso durante a pandemia da COVID-19. A frequência da boa mastigação foi comparada em cada nível das variáveis independentes. Resultados: Quarenta e nove participantes responderam sobre a qualidade da mastigação. A maior parte (63\%) considerou a mastigação boa, frequência maior entre os homens (69\% contra $61 \%$ nas mulheres), idade entre 95 e 99 anos (70\%) e com autopercepção da saúde boa (67\%). Por outro lado a frequência de mastigação boa foi menor entre os centenários (50\%), viúvos (57\%) e os que perderam peso (58\%). Conclusão: A mastigação boa foi um importante preditor de manutenção ponderal nos nonagenários e centenários durante a COVID-19. Concluímos que os cuidados com a saúde oral deve também ser uma prioridade durante a pandemia.

Palavras-chaves: Perda de peso; Mastigação; Idoso de 80 Anos ou mais. 